\title{
Sustainable Origin Seal - Increasing the Brazilian Footwear Sector International Competitiveness
}

\author{
${ }^{1}$ Tereza C. M. B. Carvalho, ${ }^{1}$ Ana C. Riekstin, ${ }^{1}$ Gabriela A. Francisco, ${ }^{2}$ Ilse Guimarães \\ ${ }^{1}$ University of São Paulo (USP), Brazil \\ ${ }^{2}$ Brazilian Association of Companies of Components for Leather, Footwear and Artifacts
} (Assintecal), Brazil

\begin{abstract}
The Brazilian footwear sector is facing increasing global competition, having lost market share in the recent years. Considering the competitors positioning regarding quality and price, the sector has to create differentiated value through innovation, and sustainability seems the right path towards this goal. It is vital to push the sector towards more sustainable practices allied with greater quality and lower prices when possible. This paper presents a proposal of a system of sustainability indicators, the "Sustainable Origin Seal" created for adding value and increasing the companies' competitive advantage in the worldwide market. The proposal presents 52 indicators classified into four dimensions (economic, environmental, social, cultural) and three categories (obligatory, very important, desirable). The Seal comprises five maturity levels. The indicators were defined based on a survey and on the alignment with other international initiatives. In addition, we developed a software for self-diagnose concerning the compliance with the Seal and for supporting the corresponding auditing process. A survey and a case study are presented. The main contributions of this work are the development of a system of indicators that fully meets the needs of the footwear industry in Brazil, besides presenting a method for developing similar systems for other sectors.
\end{abstract}

\section{Introduction}

The Brazilian footwear industry, composed by leather, components, and footwear manufacturers is responsible - in conjunction with the textile, clothing and accessories sectors - for $6.8 \%$ of the country's GDP, and for $16.5 \%$ of the total job positions, only behind the food and beverages industries 0 . In the world, Brazil is the third in footwear production, after China and India, and the eighth in footwear exportations 0 . The sector has faced high competition, especially from China and, as a result, is shrinking - which can be perceived by the drop in sales, in the number of jobs, and in exports in the last decade 0 . To face this competition, the footwear sector has been investing in design, new technologies and sustainability - aiming to mitigate the industry's main impacts, such as the use of potentially toxic substances and diversity of working conditions.

The awareness of the negative effects of consumption patterns and the current production methods is increasing among companies and the society. Companies like Wal-Mart are already requiring from its suppliers to produce more sustainable products 0 . Large industries such as Nike and Adidas have been working in the last years to use less impactful components in their products and guarantee after consumption reuse or recycling of their products.

In this context, performance indicators have been widely used to measure the attributes and results of the production process, enabling the evaluation of the current situation regarding the business goals. These indicators are also used for communicating results [4]. In addition, they enable a deeper understanding of the business' main issues as well as highlighting important correlations that are not made evident through basic statistics. In the last years, many sustainability evaluation systems were developed, such as the Dow Jones Sustainability Index, the Corporate Sustainability Index from BM\&FBovespa (the Brazilian stock exchange), the Global Compact, the Global Reporting Initiative (GRI), and the ISO standards. This myriad of choices poses new challenges, especially for small companies, regarding which model or set of indicators to apply. Further investments in processes and mechanisms to utilize these systems are generally costly, but necessary, for allowing enhancement in competitiveness and opening new markets.

In this regard, as a way to create value and enhance the competitive advantage of the footwear industry, it is necessary to align the sector with international sustainability initiatives, a requirement to enable the inclusion of these companies in international markets, especially in Europe. This work proposes a new system of indicators (along with its development method), the Sustainable Origin Seal, since the existing systems do not fully meet the needs of the footwear industry in Brazil. The main contributions of this work are the development of a system of indicators that fully meets the needs of the footwear industry in Brazil, 
besides presenting a method for developing similar systems for other sectors.

The remaining of this paper is organized as follows: Section II discusses the related work and existing systems of indicators. Section III discusses the methodology used to develop the Sustainable Origin Seal. Section IV presents the Sustainable Origin Seal details, followed by its validation in Section V, and a case study in Section VI. The concluding remarks and future directions are given in Section VI.

\section{Related Works and Existing systems of indicators}

Sustainable development is the one that meets the needs of the present generation without compromising the ability of future generations to meet their own needs. It comprises economic, environmental, social and, more recently, cultural aspects 0 . Despite the diffusion of sustainable practices in all supply chains and the increasing number of researches in the area of sustainability, it is still at an early stage in the vast majority of companies 0 .

With the increasing concerns about environmental and social issues, many companies have implemented specific sustainability management systems in the last decade. These systems, however, are usually not integrated with the company's management system. Therefore, the management of environmental and social pillars is usually disconnected from the economic management, and the economic contribution of these pillars is generally not clear 0 . Incorporating these aspects to the company's Balanced Scorecard (BSC) is one way to bring sustainability together with the company's strategy, giving them more than a qualitative bias. According to 0, there are three ways to integrate sustainability in the BSC: (i) integrating the environmental and social aspects to the existing perspectives; (ii) adding a new perspective to consider these aspects; (iii) developing a specific scorecard.

The deployment of such systems of indicators also brings some reflections regarding the business practices, and is aligned to good corporate governance practices 0 . The need to consider sustainability strategically comes to meet the growing society's demand for more accountability and transparency from companies. In this context, there are tools for financial and non-financial demonstrations, such as the Global Reporting Initiative (GRI) directives, the Dow Jones Sustainability Indexes (DJSI), the BM\&FBovespa Corporate Sustainability Index (ISE), the Global Compact (GC), the Ethos Indicators, and the ISO standards. There are also some sectorial initiatives, such as the Forest Stewardship Council (FSC), the
Sustainable Apparel Coalition (SAC), and Biocalce, and some companies' initiatives, such as the Nike Materials Sustainability Index, and the Timberland Responsibility. The usage of these tools helps companies to identify in which areas they should work to become more sustainable.

\subsection{Existing systems of indicators}

GRI was founded in Boston in 1997, by the US non-profit organizations Coalition for Environmentally Responsible Economies (CERES) and Tellus Institute. It started as an accountability mechanism to ensure good environmental conduct in companies, and later came to include social, economic, as well as governance issues in its scope. In 2002, it became formally a United Nations Environment Programme (UNEP) collaborating organization. The guidelines published by the GRI are a globally recognized reporting guide that uses an inclusive, multi-stakeholder approach oriented to sustainability. Four generations of guidelines have been published - being the most recent the most updated and, therefore, the most complete one. In addition to them, specific Sector Guidelines have been produced for diverse industries 0 . The guide can be used by organizations of any type of industry or size and has two parts: the first deals with aspects of defining content, quality and limitations of the report, while the second deals with the company profile, management approach and indicators. The organization may file the report and certify it through external evaluation. Depending on which indicators the company met, it can get, as a result, one of the GRI levels, C, B or A, the latter being the most complete. If a certifier rates the report, the company can get the levels $\mathrm{C}+, \mathrm{B}+$ or $\mathrm{A}+0$.

The family of indexes DJSI was launched in 1999 by Dow Jones Indexes and the former Sustainable Asset Management (SAM) - a Swiss resource manager specialized in companies committed with social, environmental and cultural responsibility - currently renamed RobecoSAM. The main global index is the Dow Jones Sustainability World Index and, although several others belong to the group, the assessment methodology applied is the same. The index tracks the performance of companies in economic (also including some governance issues), social and environmental terms. Through the analysis of the answers given by a list of the largest global companies to an in-depth questionnaire, the ones with the best performance in each economy sector are selected to participate. A relativistic approach is used in this selection in order to stimulate continuous improvement through competition between the participants. This process is conducted annually. In the economic dimension, the indicators comprise corporate governance practices, investor relationship, customer relationship, code of 
conduct, risk management and other industryspecific criteria. In the social dimension, the indicators comprise labor practices, human capital development, attraction and retention of talent, knowledge management, citizenship and philanthropy as well as other industry-specific criteria. In the environmental dimension, in addition to industry-specific criteria, the company's environmental policy, environmental performance, environmental reports and the environmental management system are evaluated. The index can be used as a benchmark for investors that consider sustainability aspects in their portfolios 0 .

ISE is an instrument of the Brazilian Stock Exchange (BM\&FBovespa) created in 2005 with funding from the International Finance Corporation (IFC). Its methodology was designed by Fundação Getúlio Vargas' Center for Studies in Sustainability (GVces). The initiative was a pioneer in Brazil and had the purpose of providing an investment environment that complies with society's demands for sustainable development, as well as encouraging companies to become more ethically responsible, thus continuously improving their sustainability performance 0 . Companies with the 200 most liquid stocks on the stock exchange are invited to participate; they can volunteer to fill in a questionnaire assessment, in which seven dimensions are taken into account: general, nature of the product, corporate governance, financial-economic, environmental, social, and climate change. The companies that achieve the best overall performance in the evaluation are selected to join the portfolio limited to a maximum of 40 companies. The reports are released only upon authorization of the participating companies and the portfolio is revised and recast annually. Since 2012, the selection process has been audited by KPMG 00 .

The GC is a voluntary initiative launched in 2000 by the United Nations (UN) with the objective of aligning business operations and strategies around the world with ten universally accepted principles comprising the areas of human and labor rights, environment and anti-corruption. It provides a platform for the development, implementation and disclosure of sustainable practices complying with the principles, and relies on public accountability and transparency from the participating companies. Any company in the world can join by completing a registration form and signing a letter of commitment. After that, it is expected from them to continuously incorporate the GC principles in strategies and decision-making processes within the company in order to make practices and policies more and more complying. Although the initiative does not lodge any kind of verification mechanism, it provides support for the signatories through a range of guiding documents as well as a network for knowledge and experience exchange among them 0 .
The Ethos Indicators, a Brazilian initiative, were created in 2000 by the Ethos Institute for Companies and Social Responsibility with the purpose of being a reference set for Corporate Social Responsibility (CSR) practices, as well as increasing awareness on business executives and the society in general. Companies of any size or sector can join, as it is a self-assessment tool and not a certification. It consists of a questionnaire with 40 indicators divided in seven sections - values; transparency and governance; internal public; environment; suppliers; consumers and customers; community; and government and society. To join, the company must forward electronically the answered questionnaire to the Ethos Institute. A report comparing it with the average score from the database containing the answers from all subscribing companies, as well as with the ten companies with the best overall performance (the "benchmark group") is then sent in return. This diagnosis allows companies to map strengths and weaknesses in their practices and policies, as well as to better plan and execute these practices and policies. The tool is in constant improvement and presents a concern in being compatible with other universally accepted systems such as GRI and the GC 00 .

Two ISO standards families are directly related to the sustainability theme: ISO 14000, concerning environmental management, and ISO 26000, regarding social responsibility. ISO 14000 was launched in 1996, based on the generalist BS 7750:1992 regulation ("Specification for Environmental Management Systems"), and includes a series of environmental management standards, being the 14001 standard the most used - and the only certifiable. It is a widely known system liable to be used by companies of any size and sector. The standard comprehends the following steps: developing an environmental policy; identifying the company's activities, products and services that have interaction with the environment; identifying legal and regulatory requirements; identifying business priorities and setting objectives and targets to reduce the environmental impact; adjusting the organizational structure of the company to achieve these goals; and checking and correcting the environmental management system. All steps must be accomplished in order to the company to receive the certificate 00 .

ISO 26000, published in 2006, is a Brazilian initiative that deals with guidelines on Corporate Social Responsibility (CSR) for companies of any size and sector aiming at the implementation of a CSR management system. Although not certifiable, it is a reference tool that comprises concepts, terms and definitions. It addresses the following aspects of social responsibility: historical data, trends and characteristics; related principles and practices; core subjects and pertinent issues; integration, 
implementation, and promotion of socially responsible behavior throughout the organization and through its policies and practices; identification and engagement of stakeholders, communication commitments, performance and other information 0 .

The FSC was a pioneer initiative with the purpose of responsibly manage forest resources around the world. An independent, non-profit, nongovernmental organization created in 1993 in Mexico developed a voluntary certification system designed specifically for certifying forest-originated products. The system is based in ten universal Principles and Criteria (P\&C): compliance with laws; workers' rights and employment conditions; indigenous people's rights; community relations; benefits from the forest; environmental values and impacts; management planning; monitoring and assessment; high conservation values; and implementation of management activities. These P\&C's describe how forests should be managed to meet social, economic, environmental and cultural needs - the last version, from 2012, includes the explicit concern with carbon and climate change issues. There are three types of certification: Forest Management, Chain of Custody, and Controlled Wood. The certified products can be $100 \%$ certified or have recycled or mixed sources, and must meet certain percentage of certified origin, attested by a certifier 00 .

SAC is an organization constituted by brands, retailers, manufacturers, government and nongovernmental organizations, and academic experts working to mitigate the social and environmental impacts in the footwear and apparel industries. Its focus has been to create and implement the Higg Index, a set of tools to measure environmental and social performance of apparel and footwear producers. The first version of the index was released in 2012 and the second one, in 2013. It can be applied in three levels: Facility, Brand and Product although there is no requirement to use all of them. Through self-assessment, companies' environmental, social and labor aspects, as well as design and materials, are evaluated within each level so that companies of any size can identify improvement opportunities in order to become more sustainable throughout the production chain. The index aims also to raise awareness and engagement among stakeholders 0 .

Biocalce is a certification developed by the Technological Footwear Center from Portugal (CTCP) aiming to ensure comfort, quality, strength and durability in footwear products, manufactured only with materials free of toxic substances. Moreover, the system presents additional features that can be certified along with the "basic pack": extra care (with other toxic substances); biodegradability; use of natural materials and components; water resistance; chrome-free; PVC- free; anti-slip; vegan; use of recycled materials; low $\mathrm{CO}_{2}$ footprint; green purchase; extra comfort; and compliance with REACH standards. Companies interested in certifying their products must submit a certification request indicating the products and features they wish to accredit. The products issued are analyzed and sorted into pre-established categories and then the companies are required to send samples from the products for the CTCP laboratories to perform tests. The certificate is issued according to the tests' results and is valid for one year, with the possibility for a renewal request through updated information and new samples analysis 0 .

As companies' initiatives, we can cite the Nike and Timberland cases. The Nike Materials Sustainability Index (MSI) is a suppliers' evaluation tool that focuses on less impacting materials usage, including shoes and apparel 0 . The Timberland Responsibility program deals with supply chain management environmental and social issues 0 .

\subsection{Development of a specific system of indicators}

The existence of this myriad of systems poses a challenge to companies aiming at being more sustainable. This is even more challenging for small companies. Further investments in processes and mechanisms to address these systems are generally costly, but necessary, by allowing the enhancement of competitiveness and opening new markets.

Figge et al. 0 listed the following requirements for a system of sustainability indicators: (i) the process must integrate environmental and social perspectives to the business management; (ii) a system of indicators that meets the specific characteristics of a business unit should not be generic, it should be specific to that business; (iii) the environmental and social aspects of a business unit must be integrated according to their strategic importance. Considering these challenges and requirements, and the footwear sector characteristics, a new system of indicators is proposed, the Sustainable Origin Seal.

\section{Methodology for the Sustainable Origin Seal development}

The methodology used for the development of the Sustainable Origin Seal went through four main steps:

- Preparatory phase. This phase comprised an initial bibliographic review and the development of a current situation questionnaire to be applied in some segments of the footwear sector. These segments included, for instance: soles, laminates, 
fish leather, ink for leather colorizations, chemicals as adhesives, adornments for shoes from different materials, such metals and wood, and the whole shoe productions as sandals and sportive shoes. The questionnaire fulfillment was performed in loco and, normally, involved the factories visits, when it was even easier to identity the sustainable challenges. The survey was applied in different segments of footwear sector, and the collected data was analyzed to identify which sub-categories of indicators the Seal must comprise. These sub-categories were grouped according to the famous pillars from the triple bottom line (economic, environmental, and social pillars) 0 , including a fourth pillar, the cultural, considered as a competitive differential for the Brazilian companies.

- Review of other systems of indicators. A mapping of the other existing initiatives was performed considering the aforementioned systems: GRI, DJSI, ISE, Global Compact, Ethos Indicators, ISO Standards, FSC, SAC, Biocalce, as well as some companies' initiatives. The objective was to identify which indicators should be included in the Sustainable Origin Seal in order to align it to international initiatives and practices. From these initiatives, it can be said that GRI, due to its great adoption worldwide, and SAC, for addressing the apparel industry, including the footwear, were those that more inspired the conception of the Seal.

- Discussions with experts and the sector associations. In addition to the literature review and the investigation about other systems of indicators, the Seal premises were discussed with experts and leaders from Brazilian footwear sector and the footwear industry associations, such as Assintecal (Brazilian Association of Companies of Components for Leather, Footwear and Artifacts) and Abicalçados (Brazilian Association of Shoe Industry). As result, the main premises of the Seal were established: to be inclusive, that is, to consider the current situation of the different footwear industries' segments and the different level of engagement with sustainability practices, making feasible their participation in the Seal initiative and fostering their engagement in sustainability cause; to be aligned with the international initiatives; and to promote the Brazilian culture.

- Indicators specification. Considering the industries' current situation identified in the survey, the literature review and the discussions with experts, a set of 52 indicators was proposed. A new questionnaire was developed to define the importance level of each indicator in the footwear sector. The analysis of this questionnaire supported the definition of different maturity levels (White, Bronze, Silver, Gold, and Diamond), and the distribution of the indicators into three categories (obligatory, very important, and desirable), according to the local regulations and implementation issues. Seal.

The next section presents the Sustainable Origin

\section{The Sustainable Origin Seal}

The proposed Sustainable Origin Seal has 52 indicators organized according to four pillars: economic ("IE"), environmental ("IA"), social ("IS") and cultural ("IC'), the latter being one of the main innovations of the Seal. The indicators within these pillars are classified into three categories: obligatory ("O"), very important ("VI") and desirable ("D"). Table I lists the indicators, divided by category. Each indicator, when applicable, is evaluated according to number of employees, production volumes, or revenues.

The Seal provides four levels of certification in addition Seal an initial level of membership, the White Seal, totaling five maturity levels. This is granted when the manufacturer's membership's application is accepted, by signing a responsibility term stating that the company wants to evolve within the Seal system and improve its initiatives related to sustainable practices.

The other four levels are determined based on the company's performance in each indicator considering every company facility. It means that if the company has more than one factory, the application to the Seal and its granting should be done for each factory individually. This is necessary because companies generally have factories in different stage of sustainability engagement. One simple example is the case of energy efficiency plant floors: modern installations generally incorporate more energy efficient systems and even alternative energy generation, as solar ones. Given that, the procedure for obtaining the any of the Seal levels has to be followed by each company facility.

After the White Seal (membership), the next Seal level is the Bronze one. It is awarded upon completion of self-assessment answers (Yes/No) performed in a software platform developed for this purpose. The company must achieve a number of

Table 1. Sustainable Origin Seal Indicators 


\begin{tabular}{|c|c|}
\hline & Economic Indicators and what each evaluates \\
\hline & $\begin{array}{l}\text { IE1 - Rational Use of Water } \\
\text { If the company is using water efficiently. }\end{array}$ \\
\hline & IE2 - Rational Use of Electrical Energy \\
\hline & $\begin{array}{l}\text { IE3 - Use of Renewable and Non-Renewable Energy } \\
\text { Consumption evolution of other energy sources than } \\
\text { hydro, renewables or not. }\end{array}$ \\
\hline & $\begin{array}{l}\text { IE4 - Rational Use of Raw Materials } \\
\text { If the raw materials consumption is been optimized. }\end{array}$ \\
\hline & $\begin{array}{l}\text { IE5 - Performance Evaluation of Production Employees, } \\
\text { Monitoring and maintenance of employees, } \\
\text { competences. }\end{array}$ \\
\hline & $\begin{array}{l}\text { IE6 - Machines Productivity Control } \\
\text { Machines productivity control. }\end{array}$ \\
\hline & $\begin{array}{l}\text { IE7 - Participation in Quality \& Productivity Programs } \\
\text { Informs if the company participates in any continual } \\
\text { improvement program, like the ones based on PDCA. }\end{array}$ \\
\hline & $\begin{array}{l}\text { IE8 - Investment in Research \& Development } \\
\text { How much the company invests in } R \& D \text {. }\end{array}$ \\
\hline I & $\begin{array}{l}\text { IE9 - Treatment and Reuse of Water } \\
\text { Percentage of treated, reused or discarded water. }\end{array}$ \\
\hline I & $\begin{array}{l}\text { IE10 - Rational Use of Fuels } \\
\text { Optimization or reduction of fossil fuels use. }\end{array}$ \\
\hline I & $\begin{array}{l}\text { IE11 - Sustainable Destination of Raw Material } \\
\text { Manufactured in Excess } \\
\text { Amount of excess raw materials reused, reclassified or } \\
\text { discarded. }\end{array}$ \\
\hline I & $\begin{array}{l}\text { IE12 - Rejected Products - Recovered, Returned as Raw } \\
\text { Material or Recycled } \\
\text { Amount of rejected products recovered, returned as raw } \\
\text { materials or recycled. }\end{array}$ \\
\hline I & $\begin{array}{l}\text { IE13 - Quality Management Systems certification - ISO } \\
9001 \\
\text { If the company has ISO } 9001 \text { certification. }\end{array}$ \\
\hline I & $\begin{array}{l}\text { IE14 - Strategic Planning focusing on Sustainability } \\
\text { If the strategic planning comprises sustainability } \\
\text { directions. }\end{array}$ \\
\hline & $\begin{array}{l}\text { IE15 - Use of Alternative Sources of Renewable Energy } \\
\text { If the company uses any type of alternative energy. }\end{array}$ \\
\hline & $\begin{array}{l}\text { IE16 - Objectives and Results Disclosure } \\
\text { Transparency on objectives and results disclosure. }\end{array}$ \\
\hline & $\begin{array}{l}\text { IE17 - Local Community Employees Recruitment } \\
\text { The company impacts on the local economy. }\end{array}$ \\
\hline & Environmental Indicators and what each evaluates \\
\hline & $\begin{array}{l}\text { IA1- Raw Material Origin Control } \\
\text { Control of raw materials origin in the whole supply } \\
\text { chain. }\end{array}$ \\
\hline & $\begin{array}{l}\text { IA2 - Selective Collection } \\
\text { Total of generated waste and its destination. }\end{array}$ \\
\hline & $\begin{array}{l}\text { IA3 - Wastewater, Emissions, and Solid Waste } \\
\text { Treatment, Reusing \& Recycling } \\
\text { Destination of wastewater, emissions and solid waste. }\end{array}$ \\
\hline & $\begin{array}{l}\text { IA4 - Use of Recyclable Packaging } \\
\text { Amount of recyclable packaging used. }\end{array}$ \\
\hline & $\begin{array}{l}\text { IA5 - Packaging Use Optimization } \\
\text { Verify if there are actions to reduce packaging impacts. }\end{array}$ \\
\hline & $\begin{array}{l}\text { IA6 - Collective Transport Support } \\
\text { Percentage of employees that use transportation offered } \\
\text { by the company or public transportation. }\end{array}$ \\
\hline I & $\begin{array}{l}\text { IA7 - Development of Sustainable Products \& Services } \\
\text { Efforts on offering sustainable products and services. }\end{array}$ \\
\hline I & $\begin{array}{l}\text { IA8 - Product Development focusing on Reducing } \\
\text { Generation of Wastewater, Emissions, and Solid Waste } \\
\text { Efforts on develop products focusing on minimizing } \\
\text { impacts. }\end{array}$ \\
\hline I & $\begin{array}{l}\text { IA9 - Product Development without Toxicity } \\
\text { Efforts on developing products minimizing toxicity. }\end{array}$ \\
\hline I & $\begin{array}{l}\text { IA10 - Chemicals Consumption Control } \\
\text { Control on chemicals use in the supply chain. }\end{array}$ \\
\hline I & $\begin{array}{l}\text { IA11 - Chemicals Waste Treatment } \\
\text { Control over chemical waste treatment. }\end{array}$ \\
\hline
\end{tabular}

\begin{tabular}{|c|c|}
\hline I & $\begin{array}{c}\text { IA12 - Waste Treatment Solution for Customers } \\
\text { Solutions for clients' solid waste and wastewater } \\
\text { treatment. }\end{array}$ \\
\hline IA13 - Alignment with the Brazilian National Policy on \\
I & $\begin{array}{l}\text { Iolid Waste } \\
\text { Alignment with the policy that regulates waste treatment. }\end{array}$ \\
\hline
\end{tabular}

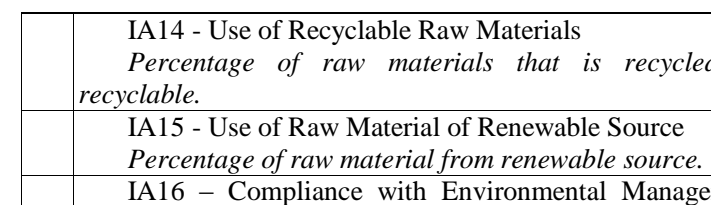

System certification - ISO 14001

If the company has ISO 14001 certification

IA17 - Replacement of chemical solvent by water-based solvent or elimination of solvent

Initiatives of substitution or elimination of chemical solvent.

Social Indicators and what each evaluates

IS1 - Safety and Preventive Health Practices

Initiatives and training focused on best working practices.

IS2 - Clean and Safe Environment

Preventive and corrective actions for a clean and safe workplace.

IS3 - Company Environment Encourages Productivity

Investment in machines, methods and processes aiming at increasing productivity.

IS4 - Compliance with Labor Laws

If the company is exempt of labor claims/lawsuit, if there is no sexual harassment cases, child or forced labor.

IS5 - Conducting Socio-environmental Programs and Campaigns among Employees, Customers and Suppliers

I Actions for disseminating sustainability best practices among stakeholders.

IS6 - People and Leadership Training

Skills management and continual improvement training

I to support leadership development, including women situation on the company.

IS7 - Additional Benefits to those established by Law

I Offered benefits compared to revenues.

IS8 - Social and Environmental Projects Support

Programs related to the environment, toxic substances, waste reduction, among others.

IS9 - Sustainability Products and Services

Existence of systematic efforts to comprise sustainability in products or services.

IS10 - Employees Education Incentive

Investment of employees' education, considering training and scholarships.

IS11 - Existence of Company-Community Integration Programs

If there is a permanent communication channel, if the company evaluates its impacts on the local community, if it disclosures its results to the community.

\section{Cultural Indicators and what each evaluates}

Values

IC1 - Protection of the Company's History, Culture and

Initiatives to protect company's history, culture and values.

IC2 - Employee's and Other Stakeholders Engagement in Preservation of Corporate Culture Programs

Percentage of stakeholders involved in the company's cultural projects.

IC3 - Promotion of Sustainability Actions focusing on Culture for Stakeholders / Employees

Programs or projects to motivate, train, and engage stakeholders in sustainability actions.

IC4 - Disclosure and Dissemination of Social Balance

I Communication initiatives about results and environmental/social impacts.

IC5 - Support for a Business Model focused on 


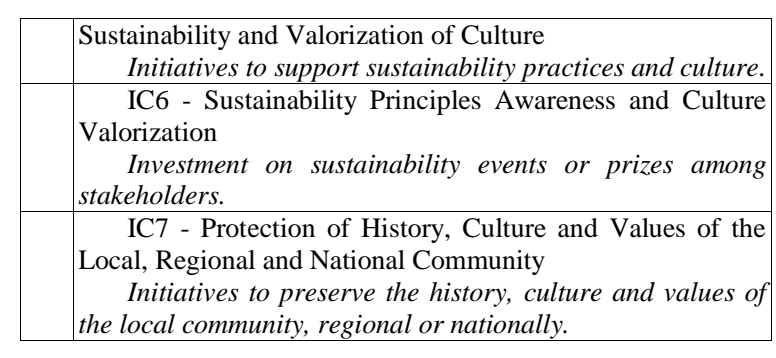

obligatory indicators defined above the average measured by the survey conducted during the development of the Seal (step iv). Since this seal is awarded after self-evaluation, the company must also certify the veracity of the information and sign a commitment statement. In order to proceed and get the Silver and Gold levels, the corresponding company facility has to pass through an auditing process. The process is performed by an accredited certifier, which involves not only the examination of documents, which proofs the compliance with the Seal indicators, but also the visit of the facility installation and the interview with key personnel in order to check some of declared information, especially those ones related to social indicators, as the inexistence of child labor.

To determine to which Seal level the company should apply for certification, the same software of self-assessment of the Bronze Seal may be used. It provides a hint about the potential company Seal level based on Yes/No self-assessment answers. The company facility is awarded the Silver Seal, after auditing, if the number of obligatory and very important indicators is above the average. The company facility is awarded the Gold Seal, after auditing, if the number of obligatory, very important and desirable indicators is above the average. The Diamond Seal requires that the company complies with all the indicators above average, as well as demonstrates progress in the indicators' fulfillment during the last two years, through auditing.

The validity of the Seal varies according to the level. White and Bronze Seals are valid for one year. Silver, Gold, and Diamond Seals are valid for two years. The complete system of indicators is planned to be re-evaluated and updated every four years.

In order to support the self-assessment, a software tool was developed to be used for membership adhesion (White level), self-analysis (Bronze level), and certification (Silver, Gold and Diamond levels), comprising the interaction between the involved institutions - the Seal manager, the interested companies and the certifiers. It is important to mention that at this time, the Seal has two accredited certifiers acting in national and international domains. Figure 1 illustrates this workflow. The validation of the final system of indicators was conducted using this tool. In addition, the software will allow the creation of a database concerning the evolution of the industry in terms of sustainability international practices adherence.

\section{Survey}

In order to validate the set of proposed indicators, their categories and the Seal levels, a survey was conducted supported by the developed software. The purpose of this first analysis was, given a significant sample of participating companies, to analyze if the Seal objectives were being met, and evaluate if the indicators were feasible and understandable.

Thirteen companies filled the self-evaluation form to achieve the Bronze level - five that have 0 to 50 employees, four that have 51 to 200 , one that has 201 to 500, and three that have over 501 employees. One of them continued the evaluation process to achieve the Gold level. The companies are from different sectors (Components or Shoes) and subsectors. Figure 2 presents the compliance of the companies with the aforementioned indicators.

The assessed companies reached high scores in the self-assessment results - two reached the Bronze level, and eleven got the Gold level. It is important to note that the Bronze Level is the one that does not demand auditing. It means that some companies during the preparatory process for getting Silver and Gold have realized that criteria for granting these levels is much more strict than they have guessed. Because of this, some of the companies are now working to evolve towards higher levels at much slower pace than expected.

Based on these results, it is possible to state that the Seal's first premise was achieved: it is inclusive, that is, it is feasible for different companies and footwear segments to pursue the Seal granting. It could also be verified that the classification of indicators into obligatory, very important and desirable is aligned to business practices, since the indicators with the least compliance were desirable ones - IE15 (Use of Alternative Sources of Renewable Energy), and IA16 (Compliance with Environmental Management System certification ISO 14001).

In the cultural pillar, the less attended indicator was a very important one, IC4 (Disclosure and Dissemination of Social Balance), not a desirable. The authors believe this is an indication of an adjustment to be made on the Seal: whether reassessing the category of the indicator, or improving the question either to be broader or to include other types of communications and reporting initiatives. The application of the system here proposed can help companies in this issue.

Two indicators also raised doubts: IE6 (Machines Productivity Control) and IA10 (Chemicals Consumption Control). In the case of IE6, laborintensive companies should have the option to answer "Not Applicable", and, in the case of IA10, 
the same applies to chemical companies. This resulted in the adjustment of the self-assessment system to allow "Not Applicable" answers to some indicators.

Summarizing the results get until now, it can be stated that the companies of Brazilian footwear sector are much more compliant with the economic and environment indicators. It is very understandable giving that economic issues are related with the company survival in the market, and environmental practices are one of the most mature in the sustainability scenario. In terms of social practices, the Brazilian companies promote a lot of actions towards social inclusion, however they somewhat sin neglecting the proper registration of these practices and other benefits conceived to the employees. Finally, the cultural pillar is the most immature due to its innovative approach and the fact that "Made in Brazil" has risen as an important flag for exportation in the last ten years.

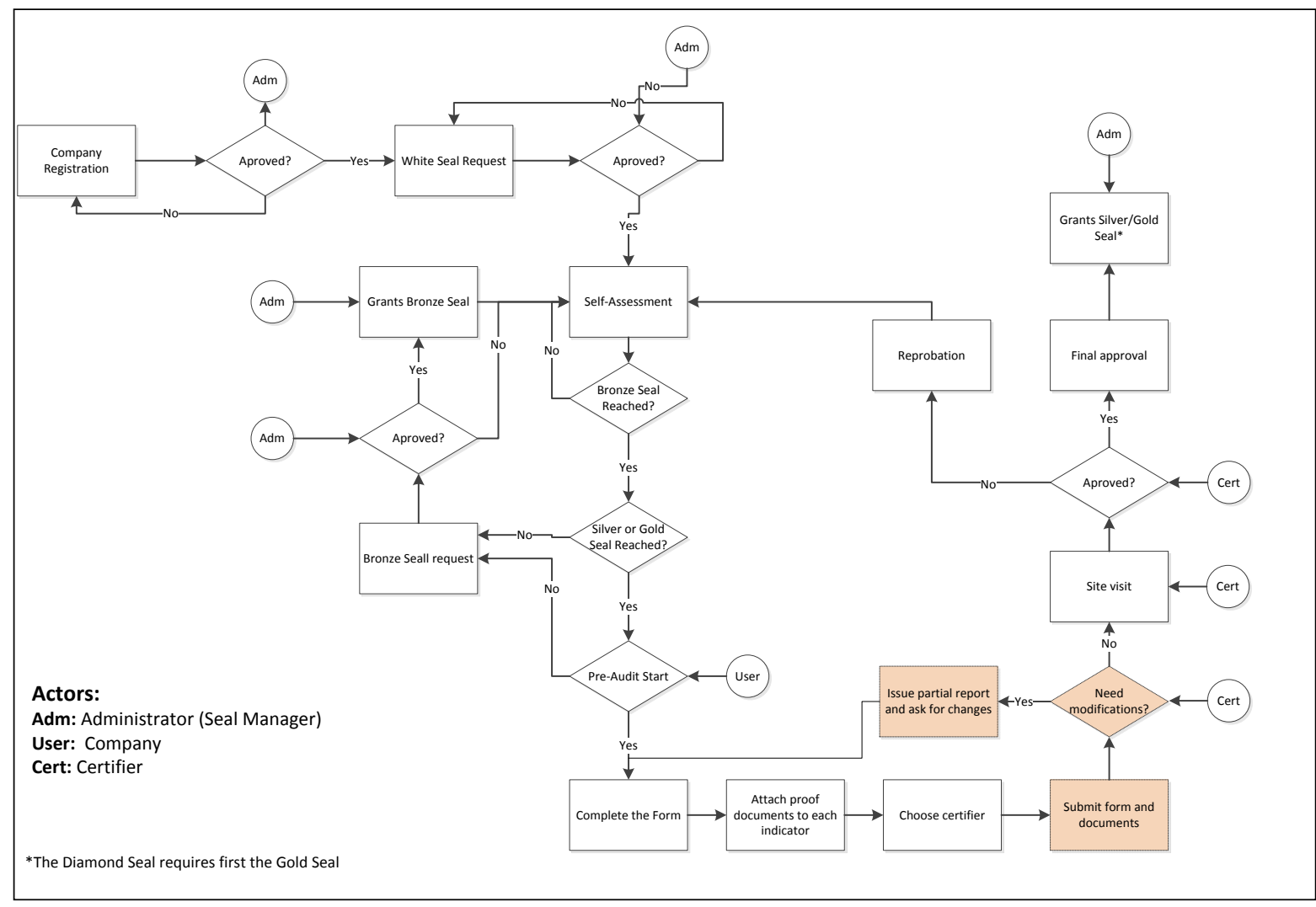

Figure 1. Sustainable Origin Seal Workflow

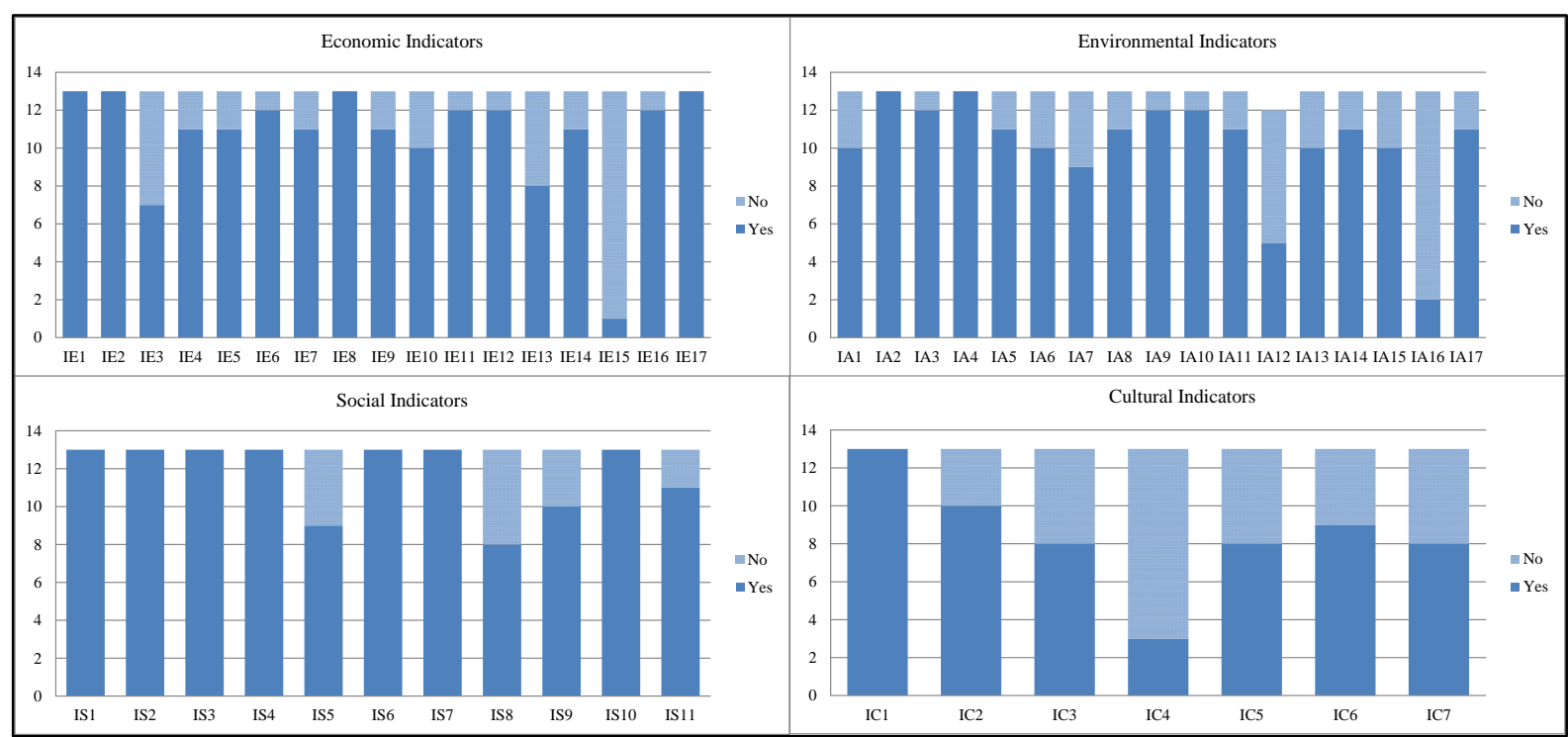

Figure 2. Survey Answers for Each Indicator 


\section{Case Study}

After evaluating the indicators in general, a case study was conducted to investigate if the detailed information asked for each indicator were feasible and understandable, and if the evidential documents were applicable. The studied company is Cipatex, and it achieved the Gold level of the Sustainable Origin Seal. It started manufacturing synthetic laminates in the 1960s, and now works with plastics, chemicals and non-woven materials. The evaluated facility produces PVC synthetic laminates, and is located in the City of Cerquilho, state of Sao Paulo, Brazil. The company has more than 501 employees.

In general, the process of filling all data was toilsome, but very educational - the companies could verify all the aspects that must be registered, followed and managed in order to have a de facto sustainable operation. Following, some highlighted points that can incur in changes in the system or become attention points in the future:

- The indicators that require water consumption control (IE1 and IE9) had their verification facilitated when the company had a closed water loop - for companies that have an open loop, some measurements devices are required along the productive process in order to measure the water input and output, which is not a common practice. In addition, there are different types of water sources. When the company deploy its own well or spring, it normally does not control the water consumption;

- Evolution was hard to be demonstrated in the rational use of raw-materials (IE4), since the amount varies according to the clients demand. For instance, if a determined raw material is used in the first semester, and another one is used in the second semester, it might not be possible to compare the use of raw materials between the two semesters;

- Some Quality \& Productive Programs (IE7) does not have a maturity level or evolution management, making it difficult to show the company's evolution in them. For instance, the Rio Grande do Sul state quality and productivity program ("Programa Gaúcho da Qualidade e Produtividade") has 3 maturity levels. On the other hand, Lean Manufacturing practices do not necessarily have associated maturity levels;

- The raw material origin control (IA1, also related to IA10) is usually only considered for the first supplier, not including other links of the supply chain;
- The waste treatment solution for customers (IA12) did not make sense for some companies that have no access to the clients' production processes;

- The Cultural Pillar presents some challenges regarding the calculation of how much was invested in the initiatives - it is important that the companies consider employees' working hours to calculate this amount. As example, let us consider the IC3 (Promotion of Sustainability Actions focusing on Culture for Stakeholders and Employees), which includes the number and the nature of developed activities and the investment done in terms of material and human resources, involving men \& women hours worked.

Some indicators demanded a new category for attendance: "partial". In the studied case, the collective transportation support (IA6) is outsourced, so the third party fuel consumption cannot be managed. In this case, there is a support for collective transportation, but it is not fully managed, thus being partially attended. In the case of wastewater, emissions, and solid waste treatment, reusing and recycling (IA3), the studied company controls wastewater and solid waste metrics, but there is no control on emissions (besides having filters in the chimneys, the emitted volume is not measured). In these cases, the company should get a proportional score, for instance 0.5 point for each indicator.

The analyzed company started the data collection by itself, but as it was the first to do that, a closer technical support was required in order to fully understand each indicator and the data required. This reflected in some adjustments in the Seal Manual, the base document for the whole process. The raised issues presented beforehand also resulted in some adjustments in the Manual.

During the auditing process, another idea was raised: to expand the certification flow including a remote evaluation phase, as illustrated by the dotted boxes in Figure 1. The interaction between the certifier and the interested company would start before the site visit, as the company uploads evidential documents in the software, and the certifier can evaluate the uploaded documents and emit preliminary evaluations until the moment that all the documents are compliant to what is established in the Seal Manual, and a site visit can be scheduled. This avoids the lack of preparation on the company's side at the moment of the certifier's visit (and consequent expenses), given that all documentation has to be uploaded to the software prior to this visit. The presented flow will also be changed to include a phase after the site visit in which the evaluated company can fix any nonconformity in a given time frame. 


\section{Conclusions}

Sustainability is a new premise for innovation and competitive advantage, which can lead to lower costs, risk reduction and increased revenues. Creating a specific certification for the footwear sector aims to bring these opportunities to a sector that has lost market share in recent years. The Seal is innovative because (i) it is specific to the footwear industry; (ii) it does not focus only in environmental and social pillars, a common practice among the other tools, making it difficult to incorporate sustainability practices into the companies' strategic planning, and (iii) it incorporates culture as a pillar, besides being inclusive and planning a step-by-step adoption.

The development of the Seal was conducted through an extensive literature review and through questionnaires to develop and validate the system of indicators. The main contributions of this work were the development of a system of indicators that fully meet the needs of the footwear industry in Brazil, besides presenting a method that can be used to develop similar systems for other sectors.

The Sustainable Origin Seal is part of a main program, called Sustainable Origin, a broader effort to promote sustainability and increase the footwear sector's competitiveness. By now, 46 companies applied to the White Level, 13 for the Bronze Level, one of which evolved to the Gold Level, one is passing the auditing process trying to achieve the Gold Level, and there are others preparing themselves to start the auditing process.

Sustainability is a new challenge and this means that the companies are not always conscious of its meaning, issues, and returns. The decision of applying or not for this certification is based on the expected return it can give. This is one of the main challenges for the Silver, Gold, and Diamond levels: to demonstrate the returns companies can achieve. The international recognition of the Seal is an important step on this regard, because it could open or create more business opportunities to companies which hold the Seal certification. The success of the Seal also depends on the number of evaluated and certified companies - the database that can be built is also valuable information for identifying sector trends in terms of innovation and sustainability related to all aspects covered to the Seal.

As future works, conducting more case studies in the certified companies is recommended to verify the current situation and deepen the understanding of the impact of this Seal in the footwear sector.

\section{Acknowledgements}

Brazilian Association of Companies of Components for Leather, Footwear and Artifacts
(Assintecal) and Brazilian Association of Shoes Industry (Abicalçados).

\section{References}

[1] Diniz Filhos, A. (2011) "Panorama do setor têxtil e de confecções". In Proceeding of Panorama do setor têxtil e de confecções. Brasília.

[2] Assintecal. "Sisinfo", Assintecal internal database.

[3] Mastroti, R.R., Souza, D.G. (2011) "Sistemas de indicadores e boas práticas de sustentabilidade empresarial", in: Amato Neto, J. (Org.). Sustentabilidade $\&$ Produção: teoria e prática para uma gestão sustentável. São Paulo: Atlas.

[4] Abicalçados (Brazilian Association of Footwear Manufacturers) (n.d.), http://www.abicalcados.com.br (10 april 2013)

[5] Oliveira, L. R., Medeiros, R. M., Terra, P. B., Quelhas, O. L. G. (2012) "Sustentabilidade: da evolução dos conceitos à implementação como estratégia nas organizações", Prod. [online]. vol.22, n.1, pp. 70-82.

[6] Hubbard, G. (2009) "Measuring organizational performance: beyond the triple bottom line", Business Strategy and the Environment 19: 177-191.

[7] Figge, F., Hann, T., Shaltegger, S., Wagner, M. (2002) "The Sustainability Balanced Scorecard: Linking Sustainability Management to Business Strategy", Business Strategy and the Environment, Vol. 11, pp. 269284.

[8] Brandão, C. E. L. (2012) "Governança corporativa no contexto da sustentabilidade", in: F. Almeida (Org.). Desenvolvimento sustentável: 2012 - 2050 - visão, rumos e contradições. Elsevier: Rio de Janeiro, Brazil.

[9] GRI. (n.d) https://www.globalreporting.org/informati on/about-gri/what-is-GRI/Pages/default.aspx (16 Janua ry 2014).

[10] Marcovitch J. (Org.) (2012) "Certificação e sustentabilidade ambiental: uma análise crítica". http://www.usp.br/mudarfuturo (23 January 2014).

[11] Sustainability Índex (n.d). Dow Jones Sustainbalibility Índex Home Page. http://www.sustainability-index.com (19 January 2014).

[12] ISE. (n.d.) <https://www.isebvmf.com.br/index.php>. Access date: 20 January 2014.

[13] UN Global Compact (n.d.), http://www.unglobalcompact.org/docs/news_events/8.1/G C_brochure_FINAL.pdf (21 January 2014).

[14] Instituto Ethos (n.d.). Instituto Ethos Home Page. www.ethos.org.br (24 Januar y 2014).

[15] ISO Standards (n.d.) ISO Home Page. wwww.iso.org. (30 January 2014). 
[16] FSC (2012) "FSC Principles and Criteria for Forest Stewardship". Version 05 (revised).

[17] Apparel Coalition (n.d). Apparel Coalition Home Page. http://www.apparelcoalition.org/ (20 January 2014).

[18] Biocalce (n.d.). Biocalce Project Home Page. www.biocalce.org. (25 January 2014).

[19] Nike (n.d.). Nike Materials Sustainability Index Home Page. www.nikeresponsibility.com (21 January 2014).

[20] Timberland (n,d). Timberland Responsibility Home Page. responsibility.timberland.com (22 January 2014). 